\title{
The Research of Safety Assessment Technology of Quayside Container Crane Based on AHP Theory
}

\author{
Hui Yang ${ }^{1}$, Weiping Ouyang ${ }^{2, *}$ and Qi Zhou ${ }^{2}$ \\ ${ }^{1}$ Shanghai International Port (Group) Co., Ltd. YiDong Container Terminal Branch, Shanghai, China \\ ${ }^{2}$ Shanghai Institute of Special Equipment Inspection and Technical Research, Shanghai, China \\ *Corresponding author
}

\begin{abstract}
Introducing the present situation and the deficiency of current regulatory system of the quayside crane, propose a new method for safety assessment. Based on the AHP theory, the safety assessment method for quayside crane was studied, a sound method was proposed. Through the definition of the equipment safety property assess value $D$, the real state and risk rank can be expressed specifically and clearly.
\end{abstract}

Keywords-quayside container crane; safety assessment; constitutive right assessment; $A H P$ theory

\section{INTRODUCTION}

The quayside container crane is utilized to load and unload containers on the shore[1]. It is widely used in ports and wharves according to its high operational efficiency. At present, there are hundreds of container bridge cranes serving in Shanghai. Part of equipment exist serious aging problems Some cranes have been used for more than 30 years, and the general design life is about 15 years, and the security authentication of the quayside container crane in service is limited to simple self-checking of enterprise and national legal supervision and inspection, which could not identify and divide the risk level of equipment. Quite a number of devices are working under the colossal risks easily leading to production safety accidents.

\section{The Safety Evaluation Method of Quayside CONTAINER CRANE}

\section{A. Comparison of Common Safety Evaluation Methods}

Introductions of several riper methods in the current safety evaluation of special equipment are shown in Table 1 .

The quayside container crane is characterized by clear structure, and the relative importance of the different components are easy to make qualitative judgment. However, making quantitative judgment is lacking a large amount of statistical data. Therefore, Weighted Evaluation Method is known as the basic method for the safety evaluation of the shore bridge.

\section{B. Weighted Evaluation Based on AHP Theory}

Analytic Hierarchy Process (AHP) method was proposed by Professor Sadie from the University of Pittsburg, which could express a complex problem as an ordered hierarchical structure diagram. The relative importance of each factor that could influence the whole core of the process was calculated by specific process to get the value of the question[4].

As shown in Fig.1, the top layer of the diagram $\mathrm{T}$ is referred to as the target layer, which refers to the problem that needs to be analyzed; The lowest layer is called as the lowest level, which refers to the basic factors that cause the problem and could not be subdivided. The layer between $\mathrm{T}$ and $\mathrm{a}$ is called the middle layer, which represents all the intermediate steps involved in causing the problem[5].

The experts rate the importance of each influencing factors that make up the logical structure model according to certain method and carry out the data processing, which could obtain the results of each influencing factor on the importance of the target layer $\mathrm{T}$.

\section{The Study on Safety Evaluation of QuAyside CONTAINER CRANE BASED ON AHP THEORY}

\section{A. The Hierarchical Division of Safety Evaluation Model for Quayside Container Crane}

According to the structure characteristics of the quayside container crane, the safety performance of the crane can be divided into four levels (as shown in Fig. 2).

\section{B. B. The Determination of Weights Value of The Evaluation Indexes}

1) Establishing the comparison matrix and obtaining the largest feature vector

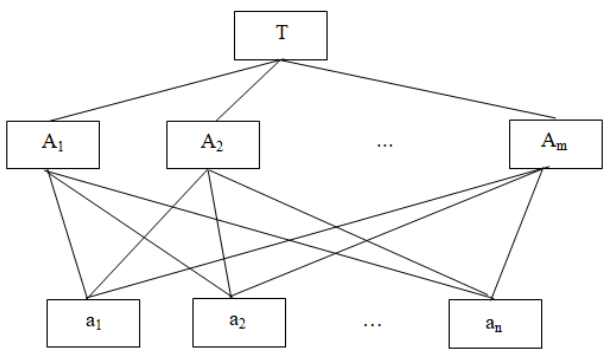

FIGURE I. HIERARCHICAL MODEL DIAGRAM 
TABLE I. SEVERAL RIPER METHODS IN THE CURRENT SAFETY EVALUATION[2-3]

\begin{tabular}{|c|c|c|c|}
\hline Method & Basal Principle & Representative Methods & Application and Characteristics \\
\hline $\begin{array}{l}\text { Index Assessment } \\
\text { Method }\end{array}$ & \begin{tabular}{|} 
Select the evaluation project according to the \\
evaluation object, and determine the scoring range of \\
evaluation project according to certain principles. \\
The total score is calculated by exponentials using \\
the grade of every project by professional evaluators.
\end{tabular} & Dow Process Mond Process & $\begin{array}{l}\text { Mainly used in the production involving the } \\
\text { evaluation of energy conversion }\end{array}$ \\
\hline $\begin{array}{l}\text { Accident Tree } \\
\text { Analysis }\end{array}$ & System security based on probabilistic risk analysis & Accident Tree Analysis & $\begin{array}{c}\text { Mainly used in aviation and aerospace } \\
\text { industry, besides new developing high-tech } \\
\text { industry }\end{array}$ \\
\hline Bayes Net Method & $\begin{array}{c}\text { Bayes network was introduced to Accident Tree } \\
\text { Analysis based on numerical analysis }\end{array}$ & $\begin{array}{l}\text { Fuzzy Analytical Method, Fuzzy } \\
\text { Probability Method }\end{array}$ & $\begin{array}{c}\text { Suitable for real-time and dynamic } \\
\text { assessment of production systems; large cost } \\
\text { for numerical computation } \\
\end{array}$ \\
\hline $\begin{array}{c}\text { Weighted } \\
\text { Evaluation Method }\end{array}$ & $\begin{array}{l}\text { Obtain the required safety indicators through the } \\
\text { modeling and quantification of the evaluation } \\
\text { problem }\end{array}$ & $\begin{array}{c}\text { AHP (Analytic Hierarchy Process) } \\
\text { Method }\end{array}$ & $\begin{array}{c}\text { Widely used, especially suitable for the } \\
\text { condition of the lack of necessary statistical } \\
\text { data. }\end{array}$ \\
\hline
\end{tabular}

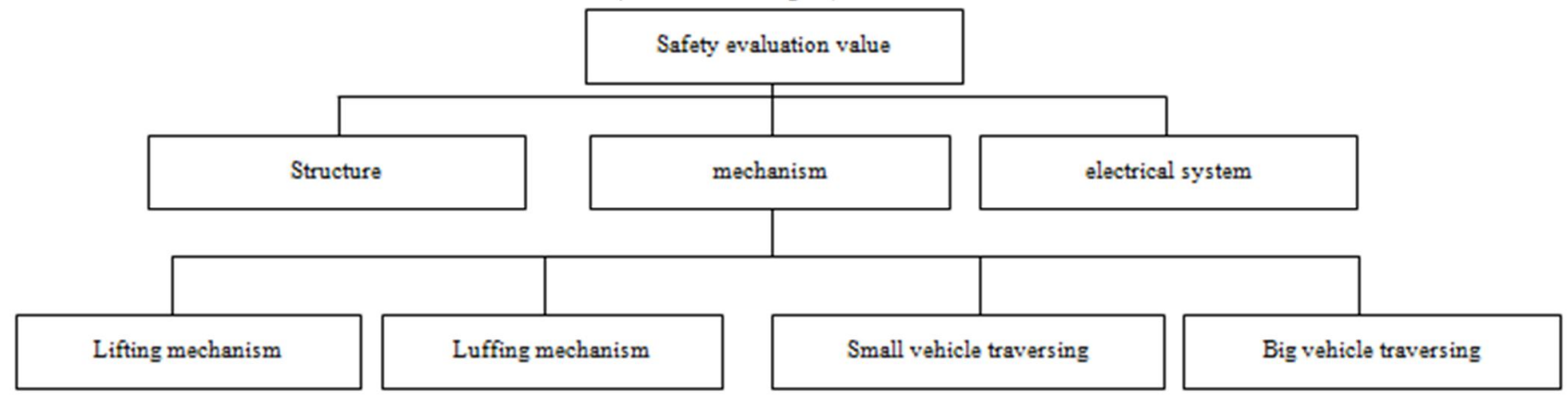

FIGURE II. THE SKETCH MAP OF SAFETY EVALUATION OF QUAY SIDE CONTAINER CRANE

TABLE II. 1-9 MAGNITUDE SCALE AND ITS IMPLICATIONS

\begin{tabular}{|c|c|}
\hline Scaling & Implications \\
\hline 1 & Comparing the two factors, the importance is the same \\
\hline 3 & Comparing the two factors, the former is a little more important \\
\hline 5 & Comparing the two factors, the former is obviously important \\
\hline 7 & Comparing the two factors, the former count much important \\
\hline 9 & Comparing the two factors, the former is extremely important \\
\hline $2,4,6,8$ & The intermediate value of the above comparison \\
\hline
\end{tabular}

After the establishment of the safety assessment model of the crane, the influence degree of each evaluation index on the relevant evaluation index of the upper level could be obtained by solving the maximum eigenvector of the comparison matrix between the evaluation indexes. Each values of the comparison matrix is obtained by the representation of the relative importance of the evaluation index of the bridge across the crane by experts based on the 1-9 magnitude scale (as shown in Table 2) [6].

It can be seen at Fig.1, the relative importance of each factor in the second layer relative to the first level factor, $\mathrm{T}$, is determined by 1-9 numbers, the scaling expression can be expressed as a comparison matrix as shown in Table 3 . The maximum eigenvector of the matrix $\mathrm{T}$ can be calculated by the sum product method, thus the coefficient $\omega(\omega=0.566,0.242$, 0.192 ) of importance of the second layer to the target layer $\mathrm{T}$
TABLE III. THE COMPARISON MATRIX OF SECOND LAYER FACTORS TO TARGET LAYER T

\begin{tabular}{|c|c|c|c|}
\hline T & A1 & A2 & A3 \\
\hline A1 & 1 & 4 & 2 \\
\hline A2 & $1 / 4$ & 1 & 2 \\
\hline A3 & $1 / 2$ & $1 / 2$ & 1 \\
\hline
\end{tabular}

can be obtained.

2) The consistency verification of the comparison matrix

According to the AHP theory, only the random consistency ratio of each comparison matrix $\mathrm{CR}$ satisfies $\mathrm{CR}<0.10$, the comparison matrix consistency is verified. And the maximum characteristic root of the comparison matrix $\lambda \max$ can be obtained by Eq.1:

$$
\lambda \max =\sum_{1}^{\mathrm{n}} \frac{(\mathrm{A} \omega) \mathrm{i}}{\mathrm{n} \omega \mathrm{i}}(\mathrm{i}=1,2 \ldots \mathrm{n})
$$

The comparison matrix consistency index $\mathrm{CI}$ is shown in Eq.2:

$$
\mathrm{CI}=\frac{\lambda \max -\mathrm{n}}{\mathrm{n}-1}
$$


The comparison matrix average random consistency index RI can be obtained by the RI order table, and the matrix random consistency ratio $\mathrm{CR}$ can be expressed as:

$$
\mathrm{CR}=\frac{\mathrm{CI}}{\mathrm{RI}}
$$

According to Eq.1, the largest characteristic root of the matrix $\mathrm{T}$ is $\lambda \max =3.024, \mathrm{CI}=0.012$, and the value of three order matrix could be obtained from the RI order table(RI=0.58). The CR can be calculated, therefore, according to Eq. 3 by $\mathrm{CR}=0.02<0.10$, so the consistency of the matrix $\mathrm{T}$ is acceptable.

Similarly, the CR value of other comparison matrix could be calculated and every CR value is less than 0.10 . Therefore, the safety evaluation model of the quayside container crane based on AHP theory is available.
THE SAFETY PROPERTY ASSESS VALUE D AND THE RANGE DEFINITION

On the basis of the inspection of the equipment, the inspection personnel give grade to each evaluation index (the best condition for evaluation index is one hundred points). After each index is normalized, the real-time state score I of each evaluation index is obtained, and the D of the safety property assess value $\mathrm{D}$ of the equipment can be calculated according to the Eq.4. The real-time security status and risk level of this crane could be understood, therefore.

$$
\mathrm{D}=\sum_{1}^{\mathrm{n}} \omega \mathrm{i} * \mathrm{Ii}(\mathrm{i}=1,2 \ldots \mathrm{n}, 0 \leq \mathrm{D} \leq 1)
$$

According to the characteristics of the crane, the security states and the required measures is defined by the experts corresponding to different values of $\mathrm{D}$, as shown in Table 4.

TABLE IV. THE SAFETY STATES AND REQUIRED MEASURES CORRESPOND TO DIFFERENT D VALUES

\begin{tabular}{|c|c|c|}
\hline D value & safety states & required measures \\
\hline$>0.8$ & Slight risk & the risk could be negligible \\
\hline $0.6 \leq \mathrm{D}<0.8$ & Low risk & $\begin{array}{r}\text { The equipment is in good condition relatively, but it } \\
\text { needs to be monitored actively }\end{array}$ \\
\hline $0.4 \leq \mathrm{D}<0.6$ & moderate risk & $\begin{array}{r}\text { The equipment can work normally, but it needs to be } \\
\text { repaired or replaced to ensure the safe operation }\end{array}$ \\
\hline $0.2 \leq \mathrm{D}<0.4$ & High risk & Outage overhaul \\
\hline$<0.2$ & Extreme risk & Outage overhaul or retire \\
\hline
\end{tabular}

\section{CONCLUSION}

A new safety evaluation method, based on AHP theory, of the quayside container crane was proposed in this paper, the following conclusions are drawn after the research:

As the characteristics and imperfect supervision system of the quayside container crane in service, it is necessary to carry out safety evaluation of risk grade identification and risk classification.

Through the research of safety evaluation based on weighted evaluation AHP theory, a suitable method for safety assessment of in-service quayside container crane is established, and the real time state and risk level of the equipment can expressed by the safety evaluation index $\mathrm{D}$, this provides an effective and convenient method for equipment supervision.

\section{REFERENCE}

[1] AICHE. Dow's Chemical Explosion Index Guide. First Edition.1994.

[2] Banon H, Biffs J M, Irvine HM. Seismic damage in reinforced concrete frames. Journal of Structural Engineering, 1991, 107(9):1713-1729.

[3] Wang ML, Shah S P. Reinforced concrete hysteresis model based on the damage concept. Earthquake Engineering and Structural Dynamics, 1997, 15(8):993-1003.

[4] Park Y J, Ang AH-S. Mechanic seismic damage model for reinforced concrete. Journal of Structural Engineering, 1995,111(4):722-739.

[5] RG Yang, GL Xu, XF Shu. The safety evaluation of overhead traveling crane based on unknown measurement theory. Journal of safety and environment, 2011

[6] H Huang. Study on safety performance evaluation method of port crane metal structure, Doctoral Dissertation[J], 2008. 